\title{
Altimetry in Marginal, Semi-Enclosed and Coastal Seas. Part I: Marginal and Semi-Enclosed Seas
}

Lakshmi H. Kantha, Diane M. Beitzell, Scott L. Harper and Robert R. Leben

Deparment of Aerospace Engineering Sciences

Colorado Center for Astrodynamics Research

University of Colorado, Campus Box 431

Boulder, CO 80309-0431

(303) 492-3014

kantha@boulder.colorado.edu

L.Kantha (Omnet)

19970717102

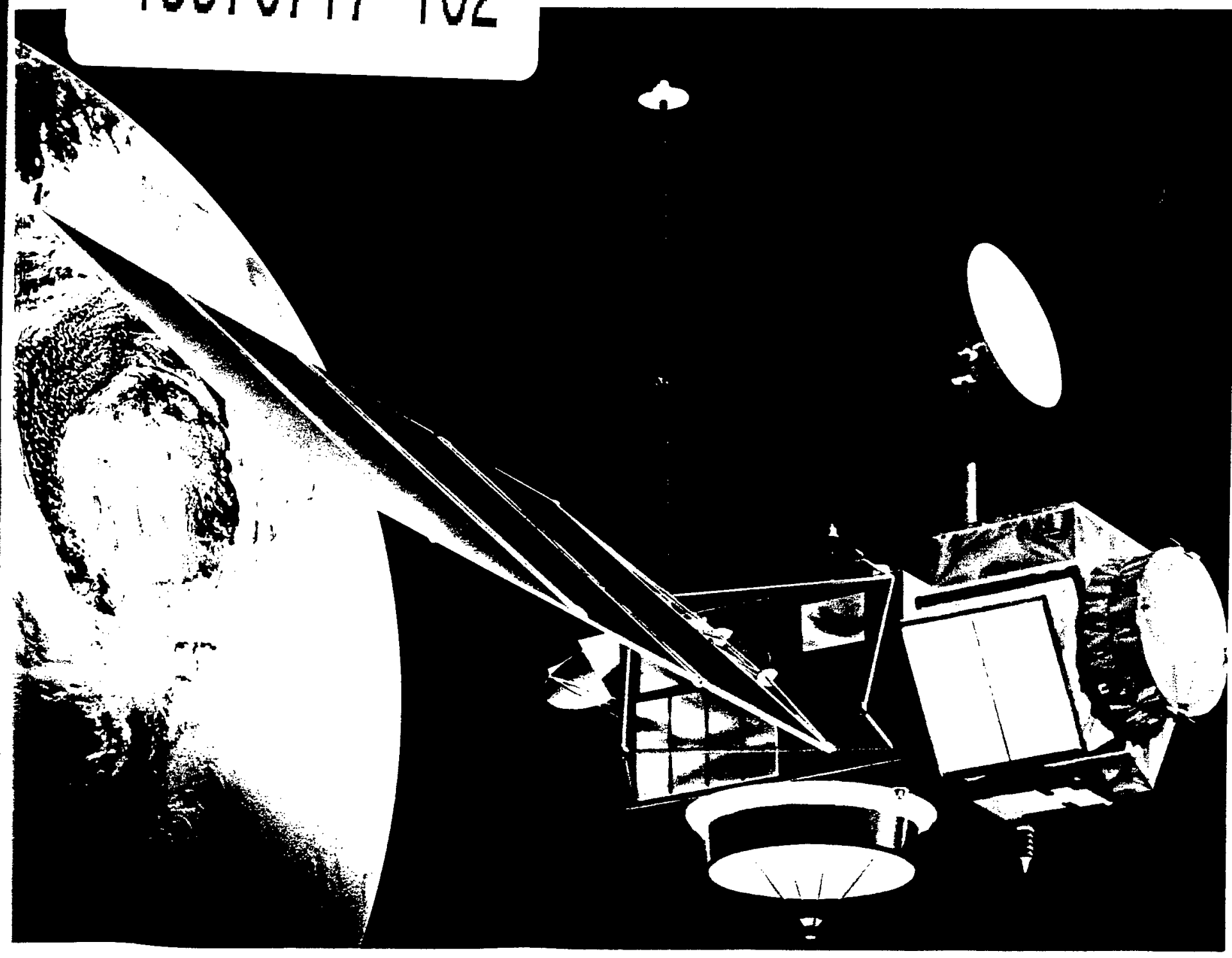


The objective of this research is to deduce subtidal sea level anomalies in marginal, semi-enclosed and coastal seas around the world from altimetric observations so that this data resource can be used both by itself and in conjunction with numerical circulation models to better understand and predict the circulation in these seas. The regions of interest include bodies of water that form the periphery of the principal ocean basins, both here and abroad as shown in the world bathymetry map (Figure 1).

To deduce subtidal sea surface height anomalies, it is necessary to subtract the tidal signals. The tidal sea levels can not at present be obtained accurately except perhaps in the primary ocean basins. A high resolution, data-assimilative, barotropic tidal model suitable for application to any marginal, semi-enclosed and coastal sea has therefore been formulated. The model is fully relocatable and nestable. It is therefore quite well-suited for subtracting tidal signals from altimetry and deducing sub-tidal features. The reader is referred to Kantha, Pontius and Ananthraj (1994) for details of the tidal model.

We have processed both historical data from the GEOSAT Exact Repeat Mission (ERM) and Geodetic Mission (GM), as well as near-real time data from the NASA/CNES TOPEX/POSEIDON and the ESA ERS-1 altimeters. The data was linearly interpolated to a reference ground track after removing the mean sea surface. The along-track data also were corrected for short wavelength geoid errors. Standard polynomial detrending by least squares fitting was then used to remove any residual orbit error. An additional benefit of this detrending is the removal of long wavelength errors and any systematic bias in the measurements of mean surface.

Dynamic sea surface height anomalies from TOPEX/POSEIDON and ERS-1 have been compared to IR imagery from AVHRR in both the Indian Ocean (Kantha, Leben, Born, Beitzell, Harper and Kindle 1994) and Mediterranean Sea. The Somali Jet, the Great Whirl (centered about $7^{\circ} \mathrm{N}, 53^{\circ} \mathrm{E}$ ), and the cold tongue off the northern tip of Somalia (wrapping around the Great Whirl) are clearly discernible in both the IR image and the altimeter data off the coast of Somali in the Indian Ocean (Figure 2). In the Mediterranean Sea, the Crete Eddy (centered about $34^{\circ} \mathrm{N}, 27^{\circ} \mathrm{E}$ ) is seen as a high anomaly in the altimeter data and as a warm feature in the IR image during the winter of 1992 (Figure 3).

Dynamic sea surface height anomalies from TOPEX/POSEIDON have also been compared to drifter buoy data from MEDS data base in the Sea of Japan (Figure 4), the Gulf of Mexico (Figure 5), and the Mediterranean Sea (Figure 6). In these figures, the color code indicates the day in the 10-day TOPEX cycle when an altimeter track was laid down. The path of the buoy is indicated by the large color circles, where the color indicates the corresponding time during the altimeter cycle. In all three regions, the anticyclonic motion of the buoys is seen to correspond to a high sea surface anomaly. A small eddy near $39^{\circ} \mathrm{N}, 134^{\circ} \mathrm{E}$ along the $40^{\circ} \mathrm{N}$ front can be seen in the Sea of Japan. In the Gulf of Mexico, an eddy shed from the Loop Current is clearly seen near $23.5^{\circ} \mathrm{N}, 264^{\circ} \mathrm{E}$. Finally, the Crete Eddy (near $34^{\circ} \mathrm{N}, 27^{\circ} \mathrm{E}$ ) can again be seen in the Mediterranean Sea along with another eddy centered near $39^{\circ} \mathrm{N}, 3^{\circ} \mathrm{E}$.

Altimetric results are now available for most of the semi-enclosed and marginal seas shown in Figure 1. The reader is referred to a report by Kantha, Beitzell, Harper and Leben (1994) as well as the corresponding multi-media NCSA Mosaic document: http://www.cast.msstate.edu/Altimetry for altimetric results from past altimetric missions as well as the current missions in almost near-real time.

Altimetry in coastal oceans, and semi-enclosed and marginal seas, by itself and in conjunction with accurate numerical circulation models, would be of benefit to combating environmental pollution in these areas, in close vicinity of which more than half the current 
burgeoning world population resides. It will also be of use to naval applications in view of the current shift in the strategic priorities of the US Navy from the deep blue waters to littoral areas.

\section{Acknowledgments}

This work was supported by the Coastal Sciences Section of the Office of Naval Research under contract number N00014-92-J-1766 administered by Dr. Thomas Kinder and the NOMP program of the Office of Naval Research under contract number N0001492-J-1572, administered by Mr. Bob Peloquin. Support was also provided to LHK under IPA support by NAVO under contract number IPA- Support was provided to RRI also by supported by JPL contracts 957388 under the Bering Sea Fisheries Oceanography Coordinated Investigation (FOCI), grant number NA16RG0490-01.

\section{References}

Kantha, L., R. Leben, G. Born, D. Beitzell, S. Harper and J. Kindle, TOPEX/Poseidon near real-time altimetry in the north Indian Ocean, to appear in WOCE Newsletter, 1994.

Kantha, L., D. Beitzell, S. Harper and R. Leben, Altimetry in marginal, semi-enclosed and coastal seas. Part I: Marginal and Semi-Enclosed Seas. Univ. of Colorado, Colorado Center for Astrodynamics Research Report, 1994 (Also available as a multimedia NCSA Mosaic document: http://www.cast.msstate.edu/Altimetry).

Kantha, L. H., P. E. Pontius and V. Anantharaj, Tides in marginal, semi-enclosed and coastal seas. Part I: Sea surface height. Univ. of Colorado, Colorado Center for
Astrodynamics Research Report, 1994 (Also available as a multi-media NCSA Mosaic
do document: http://www.cast.msstate.edu/Tides2D). 


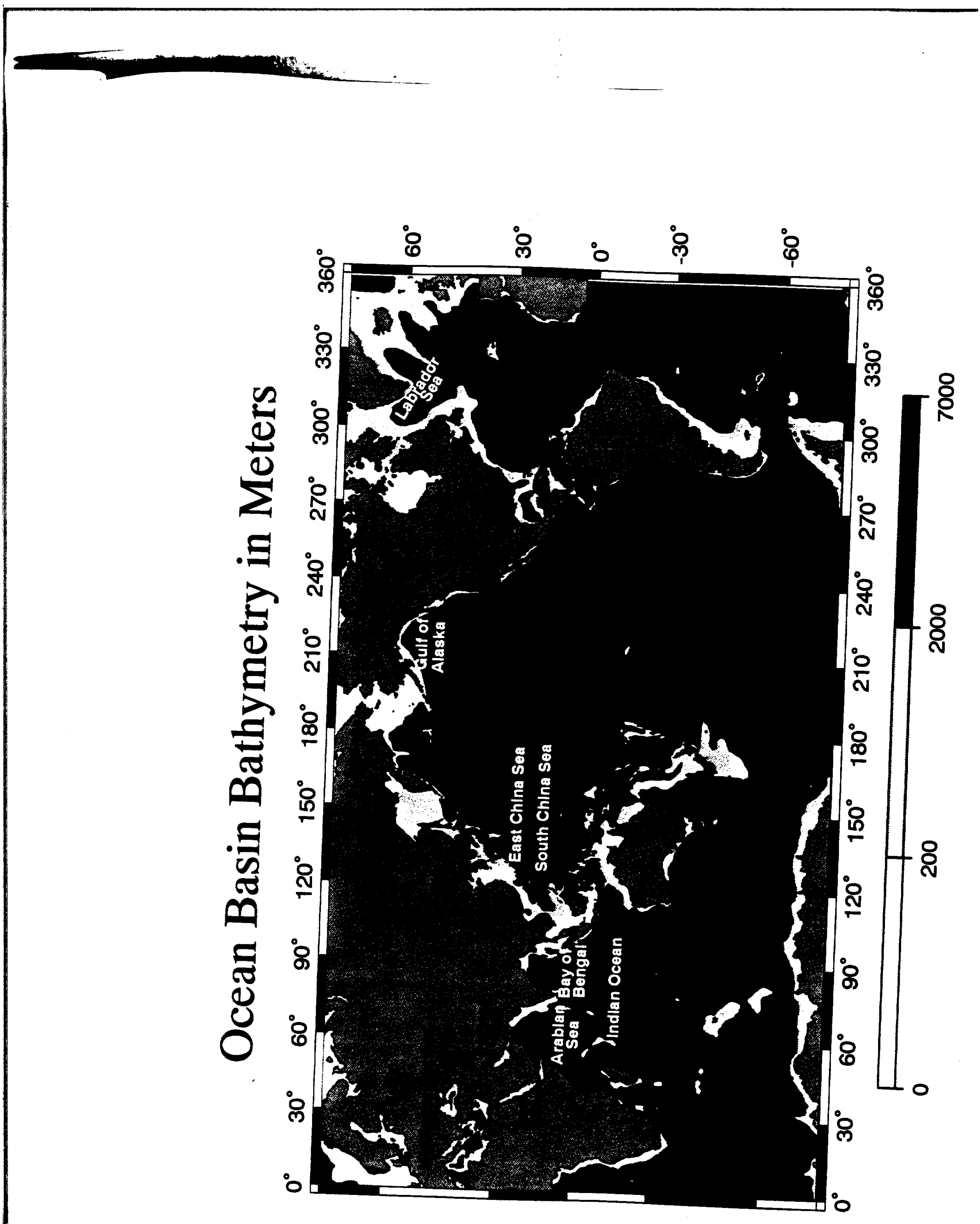




\section{Somali Current Dynamic Height Anomaly}

TOPEX Cycle 29 - June 27 to July 7, 1993

w.r.t. (L49) Rapp Mean and one-year Topex Mean
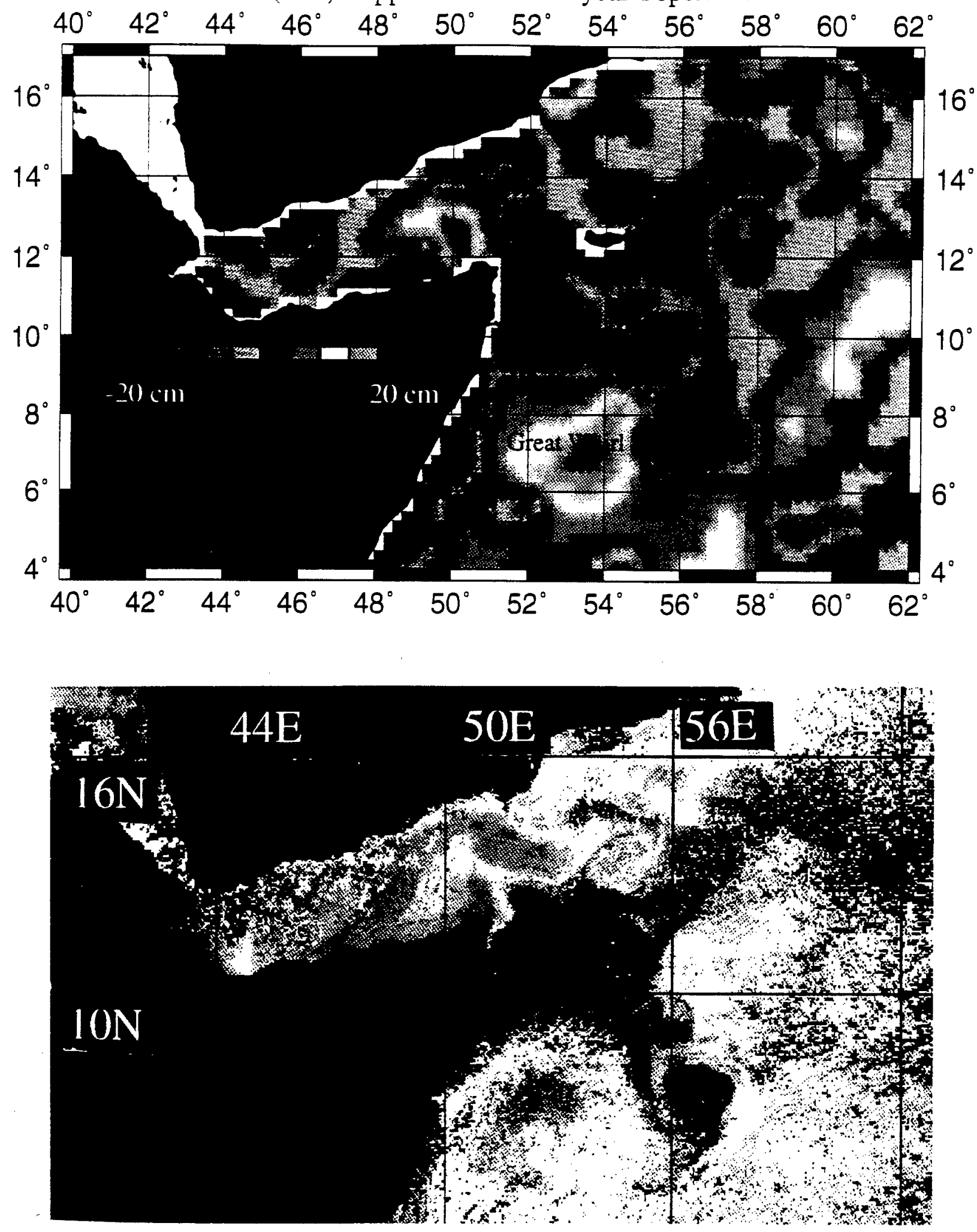

Somali Current Composite IR Imagery

June 29, 1993 - July 1, 1993 
Mediterranean Sea Dynamic Height Anomaly

TOPEX Cycle 8 - Dec 1 to Dec 11. 1992

Combination of TOPEX and ERS-1

with (75) tidal corrections

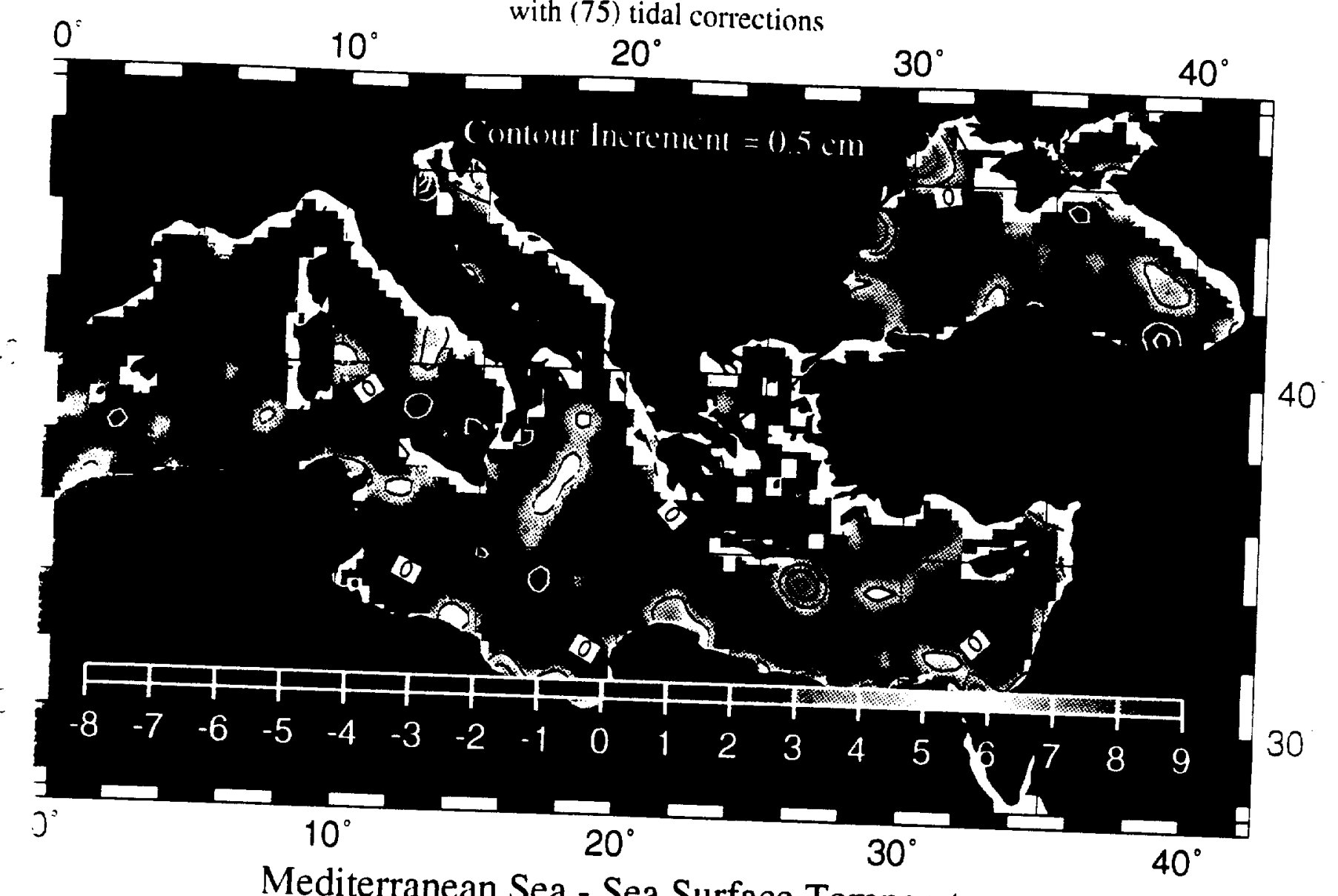

Mediterranean Sea - Sea Surface Temperature

Composite AVHRR Data

One week average centered on Dec 2. 1992

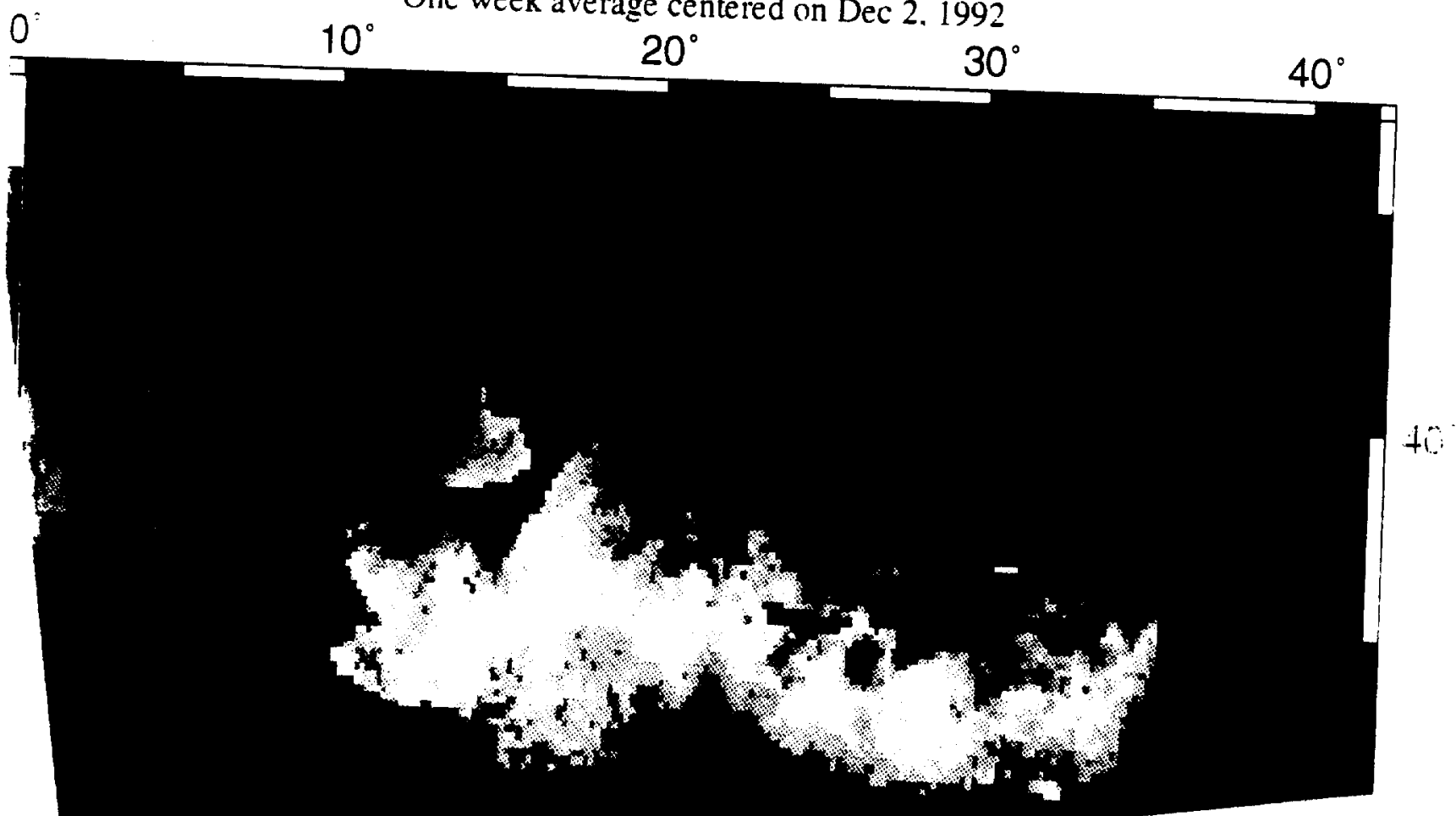


Sea of Japan Buoy Tracks

TOPEX Cycle 32 - July 27 to Aug 6. 1993

w.r.t. one-year TOPEX mean
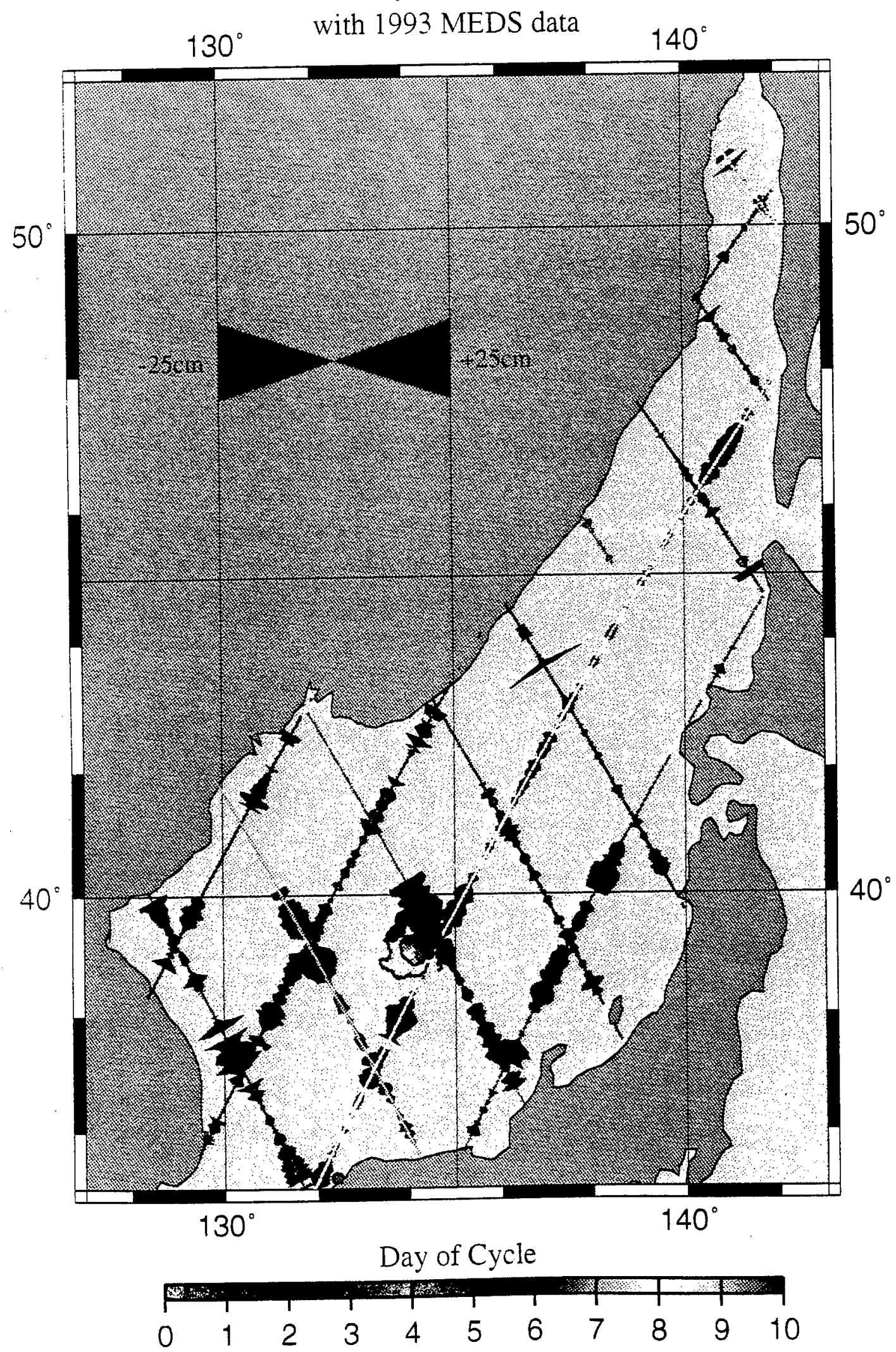


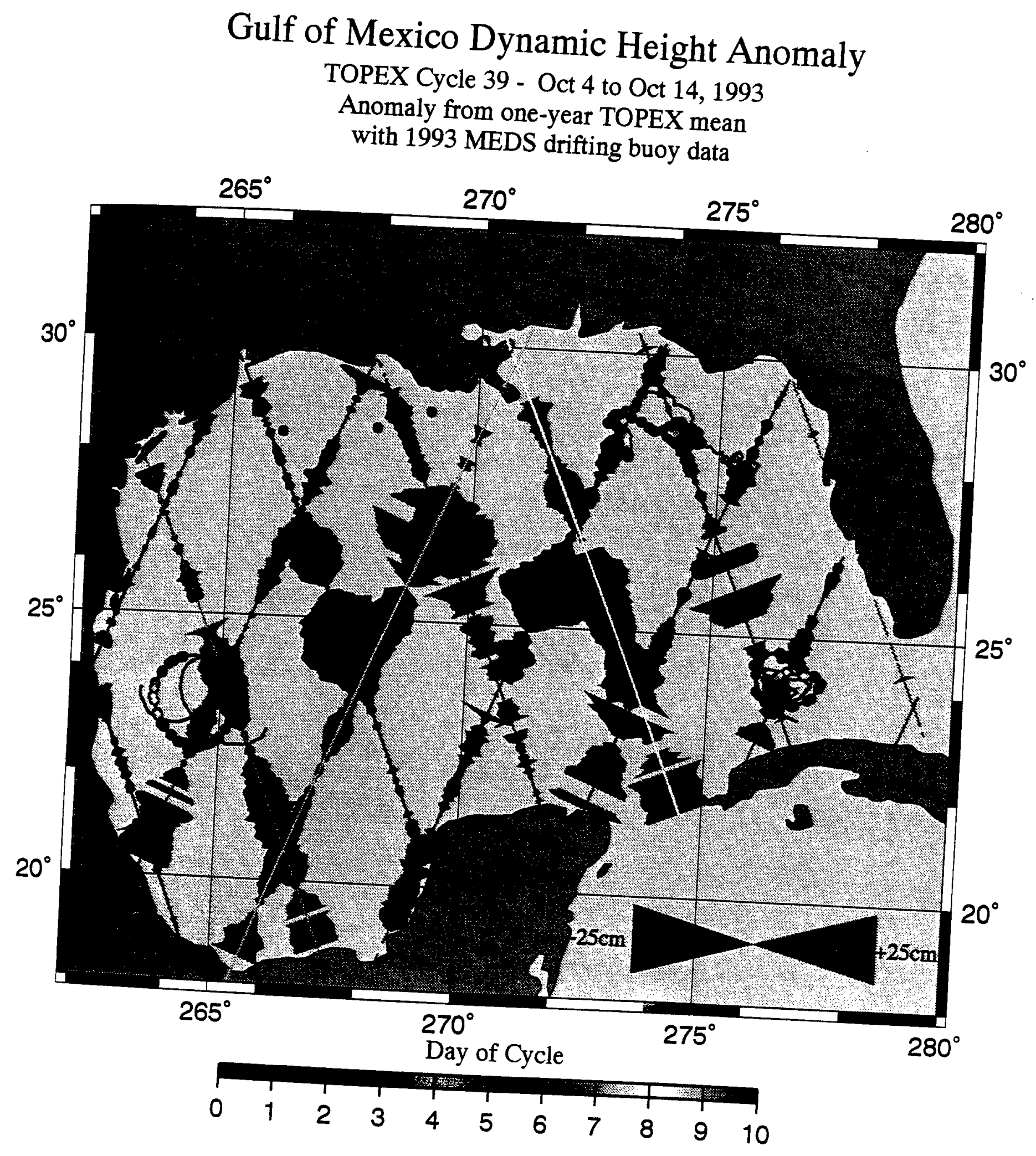




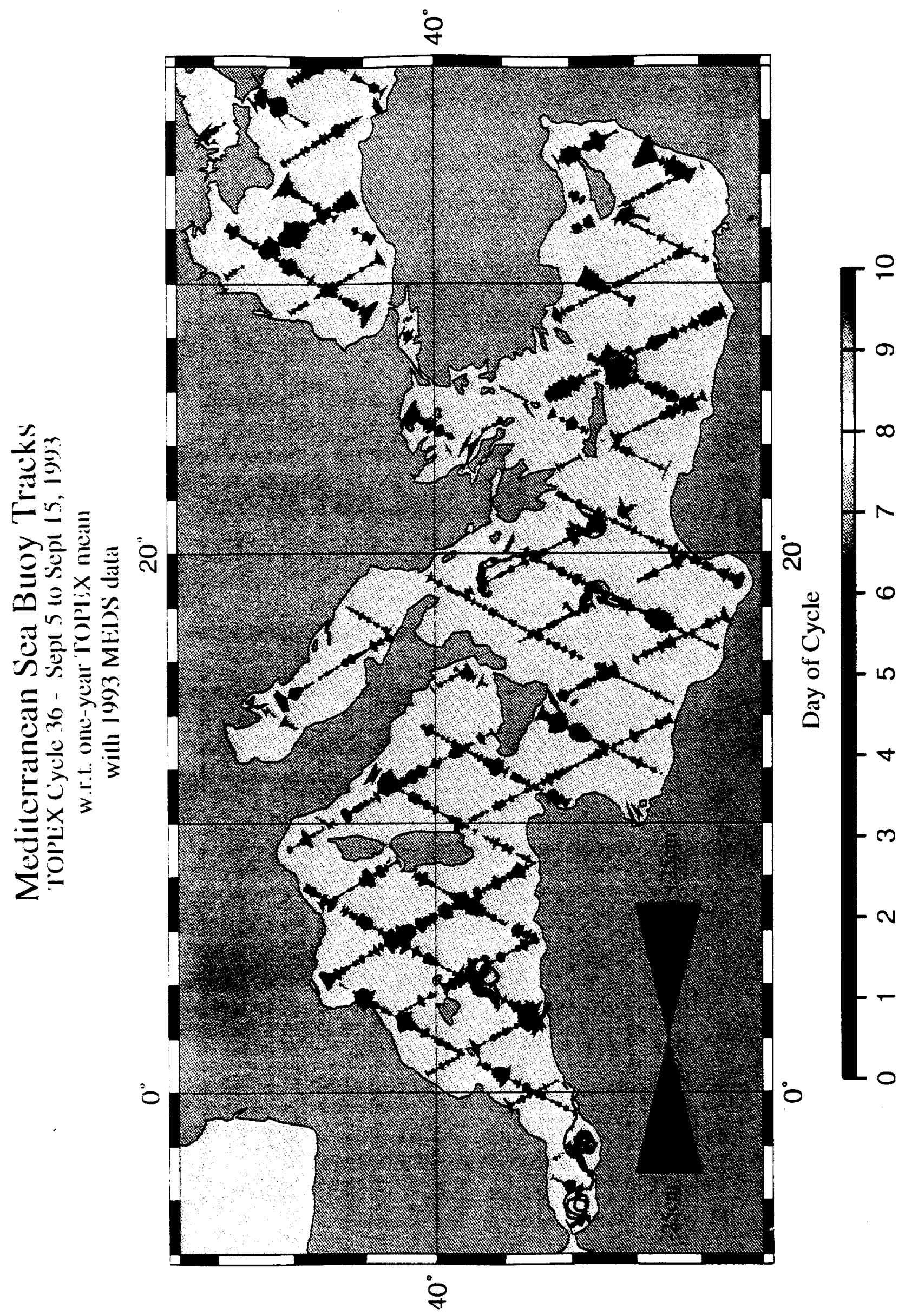

